\title{
Modelling Equality in the Midst of Religious Diversity: Lessons from Beyond Europe?
}

\author{
Joshua Castellino ${ }^{1,2, *(D)}$ and Claire Thomas ${ }^{2}$ \\ 1 School of Law, Middlesex University, London NW4 4BT, UK \\ 2 Minority Rights Group International, London E1 6LT, UK; Claire.Thomas@mrgmail.org \\ * Correspondence: Joshua.Castellino@mrgmail.org
}

check for updates

Citation: Castellino, Joshua, and Claire Thomas. 2021. Modelling Equality in the Midst of Religious Diversity: Lessons from Beyond Europe? Religions 12: 923. https:// doi.org/10.3390/rel12110923

Received: 4 August 2021

Accepted: 19 September 2021

Published: 22 October 2021

Publisher's Note: MDPI stays neutral with regard to jurisdictional claims in published maps and institutional affiliations.

Copyright: (c) 2021 by the authors. Licensee MDPI, Basel, Switzerland. This article is an open access article distributed under the terms and conditions of the Creative Commons Attribution (CC BY) license (https:/ / creativecommons.org/licenses/by/ $4.0 /)$
The extent to which global legal systems are generated by, derived from, and adhere to European values is so widespread that it has become trite to present such an observation in conclusion to a series of high-quality essays as contained in this Special Issue. The offering of such critiques, be they the so-called Third World Approaches to International Law, or earlier Marxist or Feminist insights have also become imbibed into the dominant approach under neatly categorized approaches that are usually addressed (and considered dealt with) at the start of many legal discourses. More literature in the realm is now welcomed more regularly than before in scholarly circles, but rather than see it influence the dominant discourse, it is often pointed to as showing how accommodating the dominant, heavily Europeanized approaches to law remain.

The impact and reach of legal systems, germinated in very specific local circumstances in Europe in a bid to achieve the twinned objectives of order and justice within those circumstances, that have been transported to diverse geographies and peoples is remarkable (Orakhelashvili 2006). These systems have often legitimized the theft and subsequent transfer of territory away from those who ought to have been recognized as legitimate title bearers even by European mores (Castellino 2020a). The imposed regimes deliberately misunderstood notions of us and disrupted principles of the collective good in favor of an individualized notion of property ownership (Domínguez and Luoma 2020; NoiseCat 2017). This journey has, as a consequence overseen and legitimized a process of resource extraction for profit that has depleted global biodiversity and left the planet poised on an existential crisis as it approaches breach of its own natural boundaries. The process achieved on the back of empire building was accompanied by the spread of a dominant religion, Christianity, and for some this may have even been a legitimate spur for territorial acquisition. Yet whether it was Christianity or the more sinister goal of "Civilization" it is clear that Commerce came to be a dominant feature in ensuring the subjugation of lands and peoples beyond Europe, to European influence (Klerman et al. 2011). That the process was clothed in civility on occasion and that it was, at various points in time accompanied by genuinely progressive Enlightenment Era thinking has often been used as justification to foreclose other legitimate questions about the injustice of colonization (Carey 2018).

European domination was not the first phenomena of this type that sought such power and influence. It probably was not the most brutal despite episodes of heinous crimes, and perhaps not even the most unjust. Its lasting legacy lies however, in two specific elements of fundamental importance to this collection of essays. First the extent to which it determined the foundations for how societies outside Europe could be organized, and second in the extent to which it set the rules of global interactions by way of international law, trade and international relations. Both elements are vital in unpicking one of the questions posed by this collection of papers viz. how a better knowledge of non-European experiences may be adapted to impact upon what could loosely be called the European model(s) of religious minorities regulation.

In order to further the discussion carefully framed by the editors and driven by the authors in this volume especially in part two, this conclusion is divided into three further 
sub-sections. The first will seek to sketch a generalized, and as a consequence, perhaps superficial picture of how "non-European" legal systems have been impacted by European action. The primary aim of this sub-section is to exhort attention to the extent to which the models that may exist remains closer to their colonial origins than to any indigenous pre-colonial systems. This dampens the extent to which they could be idealized as ways forward, mainly due to a twin combination: the entrenchment of the externally imposed dominant system; and its placing into the hands of dominant majorities, albeit more local, at a point of transition.

The second sub-section offered in full concurrence with many of the chapters in this collection, seeks to cast a wide lens on why the protection of religious minorities has become vital in Europe, drawing on the impact of colonization and the movement of people, while also drawing attention to some of the experience of religious minorities in Europe. The concluding sub-section offers tentative ideas of what such a wider lens of protection could be, drawing on issues that arise with the protection of minorities within and beyond Europe.

\section{Beware the Fallacy of Models}

As acknowledged in the introduction, any commentary seeking to explore solutions concerning systems from beyond Europe would need to commence with an acknowledgement that the systems themselves have been significantly altered and impacted by European ideas. While the idea of drawing on norms based on the pre-colonial experience of indigenous peoples living in harmony with nature may seem attractive, understanding the extent to which those norms have been disrupted remains crucial (Sieder 2012). In a completely different context, the experience of the Ottoman Empire millet system of facilitating autochthonous religious communities to live by their religious laws while understanding how these intersect with other communities around them may seem enticing, however crucial misunderstandings of these and the extent to which existing schisms in identity were exploited for profit resulted in new lines on maps, significantly altered notions of kinship and varied notions concerning coherence and divergence of identities (Sharkey 2018). While the power of uniting peoples to a common goal i.e., "winning independence" or "casting away the yoke of colonialism" may have served to create independent States with an opportunity to return to more traditional values, that process has proved elusive. The consequence is the continued domination of ideas drawn from the colonial experience, and it could be argued that in many places these ill-fitting models, with cosmetic indigenized changes remain, but have been unable to either create cohesive communities with shared values, or worse, have become the source of angst, carefully nurtured by political forces for their own gain, in widening religious identity-based schisms in society (Bobowik et al. 2018).

For many indigenous peoples whose spirituality may be deeply tied with living together with and in nature, the notion that nature itself could be considered a commodity that could be extracted and used, completely undermines the very basis of that belief system. That is not to suggest that such indigenous communities did not exploit or even abuse nature at times, but to highlight that those actions would have been deemed miscreant and meriting of punishment, with attempts to restore or repair the damage being fundamental to notions of atonement. By contrast what transpired was often an external determination that the land on which such communities lived was terra nullius and that the communities who lived on these could be evicted, subjugated or contained. Further the systemized extraction, exploitation and packaging of such resources that existed within those lands beyond their sustainability were legitimized and even venerated (Castellino 2020a). Aligned with the arguments advanced by Xanthaki and Tomaselli, the idea that such resource exploitation could be pursued while fueling demand not based on need, struck at the very root of the spirituality of some indigenous peoples (Xanthaki and Tomaselli 2021). That the individuals who perpetrated such actions profited, and that others continue to profit from the systematization of such actions; that there remains no real 
spur to repair of such lands; that the rehabilitation of the communities is at best grudging where it exists at all; and worse that the exploitation simply continues with other profit accumulators, shreds to the core, any indigenous system that could become operational.

The powerful and romantic notion of independence from colonial rule has failed to create the harmonies aspired to, and instead external exploitative rulers have merely been replaced by internal ones. Further, the specific question of how such systems may accommodate others with different spiritual/religious values seems almost meaningless when external influences that came to bear created such divergences from those communities' cultural norms and resulted in such significant and continuing damage. For many communities in the post-colonial world, the restoration of their societal, spiritual or religious values requires deep inward looking, but even where this may be possible, the external ambience in which the community is located, deemed simplistically as "modernity" is further disparaging of ancient values and cultures. It has instead engendered a situation where the commercial dependence of these communities on a system, will not allow for its dismantling prior to regeneration (Ochoa Jiménez 2019). In other words, even if the communities may have an undivided desire to live by more tried and tested means, the commercial value of the lands and resources they may live on are often of such a magnitude externally that forces that seek continued exploitation for profit in a system of their own making have the upper hand in determining the continued existence of the community.

In assessing such experiences whether in indigenous communities or even in minority religious communities living in urban areas, the extent to which European domination impacts their ability to generate their own systems and models is heightened. While many factors come together in maintaining this continued hegemony a crucial reason for this may well be the endurance of externally imposed legal systems based on privileging individual and exclusive ownership. This impacts not only the very basis for the existence of many communities, majority and minority, but is also a fundamental factor of production in the "modern" system.

At a macro level these principles have translated to independent States coming into being that are the outcomes of what Lord Salisbury in 1890 deemed to be " ... lines drawn upon maps where no white man's foot has ever trod" (Jennings 1963). The consequence of this line drawing, placing communities that may have been antagonistic to each other, or at the very least may have had different trajectories, into a single unified "national" trajectory, has brought strangers into houses, forcing a renegotiating of cultural and societal mores at a rapid pace (Castellino 2008). While the ancient cities and settlements across the globe may have become significant places for interactions between cultures as global trade expanded, how these communities would operate were often deemed by the host culture, with newer incumbents making a choice to engage or withdraw. Throughout history conflicts grew as cultures clashed, and the growth in prominence of religions, especially those that believed their path to spirituality was exclusively the best, offered significant scope for dismissal of competing narratives. When the religions were combined with martial might and commercially driven quests for wealth, the exploitation, subjugation and dominance of the Other became the new normal. The ebbs and flows of history track interludes of war and peace, with the depravity of war measured in genocides and massacres while the episodes of peace were characterized by trade and intermixing of cultures generating a wider experience of prosperity despite its unjust distribution across the population.

However, unlike many previous episodes of colonial domination or subjugation the end of European colonization was characterized by the emergence and spread of the idea of a relatively monolithic sovereign independent State, that was deemed to govern territories attributed to it, usually by the preceding period under colonial rule (Deutsch and Foltz 1966). This, effectively a privatization of colonial rule, often privileged the most dominant ethno-religious group or the ones with the best links to the outgoing colonial regimes (Hopkins 2000). The new incumbents slipped into the abdicated seat of power, but were often faced almost immediately by questions over their legitimacy, the extent to which they could speak with a unified voice for all religions within the emerging 
entity and the extent to which the rules they would follow would adhere to pre-existing norms and cultures pre-colonial rule.

Confronted with the potential chaos that could dismantle colonial structures, the new incumbents were reassured by departing rulers, and the emerging "international community" dominated by these same powers, of their own legitimacy. Thus, early postcolonial rulers steered a conservative line that sought to: (a) consolidate the existence of the entity as a legitimate State; and (b) seek to focus on questions of "development", understood to be a process of addressing the widespread and entrenched poverty that had characterized the depletion and exploitation of local resources to earn profit for "entrepreneurs" in Europe. For many such emerging States, religion did not form the frontline of their precarity. In entities with overwhelming religious majorities, places as different as Malaysia and Mali, activities could be focused on the State consolidation process while providing limited rights to religious minorities, usually in return for loyalty to the idea of the emerging State, and the caveat of chilling any counter-claims to territories and alternative independences. In other States, with undivided India being among the most dramatic, religion and religious protection became a fault-line that eventually cracked and resulted in a traumatic physical bifurcation of the colonial entity on the basis of religion, with significant loss of life. Religious belief became a marker of perceived loyalty, but the differential approaches of Pakistan-formed as a religious State; and India-formed deliberately as a secular State that was welcoming of religious diversity, lay in sharp contrast (Khosla 2020). However almost to prove the hypothesis being advanced here, the failure of that secular vision of India, to achieve meaningful change to the colonial governance machinery and the extent to which the religious majority subsequently seized power to redefine the rules suggests that the outcomes in both States may eventually resemble each other.

While a decade ago the values of Indian constitutionalism especially in protecting religious freedoms and diversity may have been offered as an alternative model to States with a multiplicity of religions, recent attempts to dismantle that system backed by a significant majority, raises questions about its efficacy. The chapter by Choudhary on India offered in this volume clearly shows the underlying vision of Indian drafters, for what could be classed a religiously driven secularity, with its many outreaches to religious communities in terms of personal autonomy laws, the backing for establishment of institutions and the transmission of religion as an essential feature of identity alongside a secularized "national" identity (Choudhary 2021). Yet that system ultimately floundered since the visionary changes required to address the entrenched poverty, continued drain of resources and accumulation of wealth in few hands proved beyond the reach of politicians and those engaged in statecraft and governance. The result was State capture based on ideological principles, marketed as a call for the return to a notionally more hallowed period of Hindu rule (Castellino 2020b).

These necessarily revoke national compromises that were struck, mainly in the form of guarantees of protection for religious minorities. These compromises were constructed at the foundation of India to consolidate and secure the territory and construe a unified single national narrative from the complex religious (and other) identities that formed a significant part of the population. A fierce, almost militant, all-encompassing, multi-religious and secular ideology was pragmatically engineered, to forge a narrative of national identity designed to curb further hemorrhaging of land and people. The failure of that vision in reversing widespread poverty, even in the face of significant national level growth led to restlessness and frustration. This came up against a newer cultivated vision which was the driver for the dismantling of the compromises towards religious minorities that characterized the previous seven decades. In the words of Parekh who used them critically, this vision could be summed up as one where:

India should see itself not as a civilization or even a culturally embodied nationstate, but as a state like any other. It should learn the art of realpolitik, acquire political power (which alone commands the world's respect), and use it to promote national interest. Political power comes from economic and military power. 
This is what China is supposed to be doing and India must follow suit. Poverty must of course be eliminated, but that is expected to come about as a result of trickle-down effect, limited forms of rural and urban employment schemes, rural industrialization, further extension of reservations, globalization etc. Inequalities and injustice will remain and even increase, but that should not matter; and in any case it is neither the state's business nor in its power to do anything about them (Parekh 2009, p. 49).

The idea that national religious harmony would not be top of the agenda in contemporary India, and that the quest for profit, irrespective of its distribution, should instead fuel "progress" is, incredibly, the least religious driven motivation, but remains a key facet that drives "Hindutva" forward in dismantling models of religious protection.

Much of Europe now has a majority population that does not follow any religion. This is in stark contrast to every other world region where those who are at least unified in the belief that any faith is better than none, are in the majority. Europeans, even religious ones, struggle to understand the huge impact of religion on those within these societies, whether leaving to God the decision as to whether to die of COVID-19 rather than adopting preventative measures, or dictating life paths and life chances.

One lesson to be imbibed from religious minority life outside Europe is the need to bring smaller religious communities that may not be organized at the level of the big five or six world religions, into the frame. The discourse of Freedom of Religion and Belief has been dominated by discussions between States, populations and these major and highly organized (if fractured) religions. Indigenous spirituality hardly merits attention but has billions of adherents globally including much of Asia, Latin America, and in Europe among the Sami of Norway, Sweden and Finland. In the Middle East, ancient religions such as Bah'ais, Yezidis, and Kakai have recently become more visible, but only because of their increased persecution. It is easy for Europe to retreat into a false dualistic view: Christian: us (always here) versus Muslim: other (migrant) habit of thinking. Even a rapid and cursory glance at Myanmar, India, or Iraq reminds us of the much greater and to be welcomed diversity and intricacies between myriad religious communities that co-existed in the same space for millennia.

\section{How Do You React When the Whole World Comes to You?}

Irrespective of what transpired in lands beyond Europe as engaged upon in the previous section, one unquestionable result of the previous century of world politics is the presence of many communities, non-European in origin, within the lands and territories of European countries. Thus, while intra-European migration may have occurred across boundaries this is perceived as being both gradual and accompanied by relative assimilation. Religion, especially Christianity was considered by many European States to either be definitive of their identities, or in some instances to be such an unquestionable part of the national identity that it did not merit any exalted attention. It is worth bearing in mind that the transportation and dissemination of Christianity was a key driver for European incursions abroad as characterized by the Papal Bull of the 1493 given to the rulers of Portugal, with European history from previous centuries paying significant homage to the Crusades where Muslim communities are portrayed as infidels in need of civilization, with significant signs throughout of a seeping antisemitism that appears to tolerate Jews within communities but treats them with persistent suspicion. The Holocaust and its legacy shows not only the obvious dangers that exist for religious minorities, but also the fervor and sense of entitlement with which suspicions, resentment and dislikes can be fueled into a political and military venture to devastating impact.

The more recent hysteria sweeping Europe appears to have been carefully cultivated by political movements as an existential threat to European values. The perceived threat to "Christian values" is often portrayed as the key battleground, with the emergence of multi-religious communities, institutions and values seen as a threat that may sweep away a civilization. Experiments with multiculturalism, the extent to which they (minorities) 
form a challenge to "our way of life", and the promulgated view that minorities do not assimilate either in religious on linguistic terms, are all called upon as further evidence of a need to mobilize against an engineered "scourge" (Chin 2017).

The disappearance of jobs in the face of increased mechanization, the concentration of wealth in the hands of a few and the accompanied dismantling of social services by an increasingly privatized agenda have all been contributing socio-economics conditions culminating in a sense of crisis. In this crisis, the arrival of refugees and migrants were portrayed as eventually disruptive, despite a history of the positive impact of immigration on European economies and its ability to generate prosperity. The replacement of public health and education services with private oriented ones, alongside a growing demand for such services by people who are unable to afford private services has created a sense that the few resources that exist are "wasted" on foreigners, that such foreigners are lazy and only "coming to Europe" to exploit generous provisions and entitlements. The State narrative derived from Enlightenment Era ideas about its neutrality, may have been important in generating some forms of religious protections ensuring these are carefully shrouded within such a veil (Devine 2011), but as Henrard shows, these are, at best, "half-hearted attempts" that flounder easily when faced with any level of difficulty (Henrard 2021).

Instead, there are significant questions that confront Europe over the question of how to address the increasing diversity of its population. The simple "us" and "them" narratives that portray communities as European or non-European is defunct both due to the extent and sheer length of time through which communities, non-European in origin, have assimilated and become European nationals in significantly more than name. That many such communities in addition may be Christian means that they may share more in common with their "European" neighbors than their ethnic cousins, further confusing the array. As for Muslim communities who are also European and may have been for a few centuries, the assumption that they are somehow less legitimized in their presence in Europe than others must seem baffling for the manner in which it is ignorant of global history. Length of time in Europe already forms a key differentiator among minority communities in terms of the acquisition of rights, with nationality requirements becoming more strictly enforced in the face of growing xenophobia. When the combination of experiences of Europe's minorities is taken into account, a more realistic assessment would probably reveal that rather than religion it is in fact "race" that may be a key driving element. For the average European susceptible to a range of far-right options that may be available to cater for their "political" views, the religion and race of an outsider is merely collapsed into one, even though the founding push for the view may be Islamophobic. Thus, the distinctions between religious minorities, and as a consequence any remedies a State may be willing to design differentiated models of accommodation, are likely to be relatively low on the political agenda of any aspiring governance candidates.

The skewed historical narrative that remains highly selective in laying out European history is an important contributing factor to the current state of affairs. Migrant populations had many different motivations for arriving in Europe. Some were brought forcibly, others were recruited en masse for particular roles, still others arrived after being planted from one colonial outpost to another, and many arrived as a consequence of the devastation of their lands and resources which broke cyclical and subsistence-oriented economies. Europe's wealth and the differential it paid for talent compared to "home" countries also attracted significant numbers, which augmented European economies while acting as another form of resource depletion.

However as long as European history stays clear of explaining the role European countries played overseas especially in the exploitation of resources, the portrayal of minority communities, religious or other, as "scroungers" seeking to benefit from the wealth generated will continue to foster hate and division (Castellino 2020a). This has shored up the fortunes of specific types of more racist-oriented political forces, even enabling them to command majorities in the short and medium term across a spectrum of European countries. In the long term, however, the emerging internal mixing of the populations on 
an ethnic or religious footing alongside the extent to which many of these communities are likely to play a central part in the emerging economies will simply mean fractured divisive polities that are likely to face economic stagnation and ethno-religious tensions.

\section{How Should You Behave Now That You're Multi-Religious?}

The urgent need to generate a unifying "national" narrative is becoming palpable in many societies within and outside Europe. The idea that any group: a minority-religious, ethnic or linguistic, a community, a tribe, or even a majority, a "nation" or "a people" are solely defined by a single facet of their identity over every other facet would seem absurd. In what European historians refer to as the Age of Nationalism commencing around the middle of the nineteenth century, the idea of galvanizing communities was made and received as a unifying call to forge a collective future, even if it may have been misused as a ruse for colonial quests for domination. The faded calls for nationalism based on those ideas in a contemporary world may seek to reawaken that zeitgeist, but they do so, in nearly every part of the globe, in places where a history of migration, dominance, exploitation and subjugation are far greater realities. In addition, heightened awareness of the overwhelmingly patriarchal nature of systems is driving greater realization of another form of domination and subjugation that has engineered exclusivist systems, while the boundaries around gender and gendered behaviors themselves are fraying. Technological advances and awareness have enhanced the notion that disabilities that may inhibit human achievement in some realms, should not be cause for hindering the development of other realms for such individuals. Modernity with all its ills may also be facilitating the emergence of new commonalities.

In the midst of all of these significant micro challenges, twin macro crises loom above every government. The first pertains to what immediate and medium-term measures can be taken to mitigate the impact of climate change while galvanizing a metamorphosis towards long term change. The second lies in the urgent need to redesign societies in such a manner that diverse types of human endeavor can remain central in a manner that will generate financial returns to guarantee survival.

The first more obvious challenge stems from willful destruction of the environment, caused by the same forces that drove colonization and the subjugation of peoples; the second less obvious challenge lies in ensuring that economies of the future can generate work and returns to an extent where communities can thrive. Increased mechanization is eliminating certain types of human activity, with automation rendering significant unemployment. New economic activity assumes technological intensity and entire new types of endeavors are not being generated at the extent to which reduction of employment is taking place, widening systemic unemployment. The divestment of State from many essential services means that these are significantly under-resourced and overburdened in terms of demand. Even where plans exist to meet the excess demand, these are based on ever greater embracing of technological rather than human-activity oriented solutions. Faced with long term prospects of the scarcity of employment, societies appear to be reverting to a greater individualized Hobbesian world where every advantage must be utilized to get ahead. In such a febrile environment angry identity politics, drawing on one of the earliest such external markers of difference, i.e., religion, has had a significant impact, pulling apart communitarian threads and harnessing divisions in a calculated manner utilizing technological algorithms.

Maintaining the rights of all in such an environment becomes an important back marker of civilization, and guaranteeing them where they are most needed becomes a fundamental responsibility for all who believe in the inherent dignity and worth of every individual. Religious minorities in Europe today, as elsewhere in the world are among its most vulnerable populations, so a defensive mission to safeguard these rights alongside proactive steps to bring out social and economic equality need to become rallying calls to galvanize those who would protect these communities' rights. Some key lessons however 
need to be heeded, and this brief paper ends by offering five, as tentative steps towards better models.

\section{(a) Looking back at where we are: community oriented historical narratives}

Correcting the narratives about the history Europe tells itself about itself is becoming increasingly important. Notwithstanding appreciation of the role European States played in the devastation beyond its borders, understanding how its contemporary societies are constituted and how they have come about is of vital significance to the present. Multi-religious Europe has been a reality in all corners of the continent for at least three decades, but rather than accepting this, governance and societal attempts at addressing or avoiding this vary, from denial: hiding and insisting on mono-culturalism; to the tokenistic: paying lip-service to multiculturalism while not ensuring the eradication of structural discrimination. In more recent political times, this has become replaced by reminiscences about a notional hallowed time which exists in inaccurate portrayal of histories, of a glorious mono-cultural past that not only overlooks the schisms and wars fought between different Christian sects over centuries but was in fact based on rampant exploitation and domination over the rest of the world in a spirit of racial and religious superiority.

An approach beyond recrimination alongside a positive outreach to all communities, irrespective of their roles as perpetrators or victims is crucial to building vibrant societies. Respect for otherness is often most clearly manifest in religious minority communities, so commencing the process with such communities would be powerful. Historical documentation often feels like a single strand of a narrative - of what some powerful men tried to do (and usually succeeded) to other powerful men who are then portrayed as losers, and therefore less powerful. A history documenting how and what brought communities together beyond the story of political power is crucial to understanding contemporary societal forces. For many communities around the world, European as well as non-European, their personal and community histories are contained in narratives, myths and stories. Some of these are about great battles but many are about more common experiences that show how communities intersect and interact along a shared journey of contemporary living. Locating the many religious minorities into this, whether positive or negative, alongside a documentation of the stories of women, personal narratives and episodic and cathartic moments may be as valid as documentation of the past as the present thrust that relies on a narrow, elite, masculine and triumphalist band of human experience.

\section{(b) Re-articulation of European values in a contemporary setting}

Creating a new binding vision for society is becoming ever more important in the midst of fragmentation. The politics of division and anger is decimating religious and other values across a spectrum with none but a few profiteers prevailing. Instead, in very crude terms, it is segmenting societies on the basis of a single element of lived experience: white and European or non-white Other.

The richness of human diversity beyond ethno-religious identity and the many faceted talents possessed within such diversity are likely to be crucial to overcoming the current challenges and building a unified and inclusive narrative for a peaceful society that is tension free. Understanding what such a society should be beyond narrow religious markers (e.g., the "return to traditional, i.e., Christian values") would require an intercommunitarian dialogue focused on common goals, such as the availability of healthcare and education, the prospect of meaningful employment, and crucially in terms of the climate crisis, the extent to which societies can progress to mitigate this challenge. Deriving and articulating such a vision in a contemporary setting, especially based around environmental sustainability and contemporary social justice, rather than resorting to historical versions of what Europe may have been, is far more likely to create harmony and growth than attempts to pick a putative moment in the past and try and mobilize communities towards achieving it.

(c) Protection against hate speech and stigmatization 
While (a) and (b) require appreciation of the need for long term investment in accommodating religious diversity in Europe with a view towards greater sustainability, protection against hate speech and stigmatization is a more urgent short-term goal that has to be achieved. The growth in the use and abuse of social media is carefully crafting antagonisms and then using those to ignite passion and hate, with religion again being a convenient staging post. It is incumbent upon the State to ensure that all such behavior is identified and punished, but it is equally important that every religious and political institution emphasizes its underpinning values of peace, taking upon itself the role to censure all behavior from among its believers and adherents that may be harmful towards this peace. This should apply as much to statements from government and aspirants to political power and should be emphasized as a fundamental European value that if transgressed has important and recognized consequences. In addition, a stricter code of policing corporations that work in the space becomes important. Many see actions to regulate hate speech as a slippery slope which will result in severe reductions in freedom of speech. Hate speech along racial or ethnic or disability grounds is actually simpler to regulate than religious hate speech. Legitimate criticism of or debate about religion is possible in a way that does not arise with race and needs to be separated from sweeping negatives applied to those who follow any particular religion. Of course, speech that incites religious violence in the short term must always be regulated and removed, but this leaves the tricky issue of a drip, drip, erosive effect of long term, repeated lower level religious hate speech that may prepare the grounds where violence becomes inevitable or unstoppable. Significant danger lies in the culmination of millions of micro-aggressions that aggregate into harmful social attitudes and ultimately violence. It is thus imperative that collective measures are taken to eliminate erosive hate speech. That may mean "no hate" platforms in politics and the prevention of certain kinds of political participation, on the basis of actions that impinge on the rights of fellow citizens.

\section{(d) Maintenance of the neutrality of the public square}

The relationship between Church and State varies across European countries, but despite vaunted notions of laïcité, the overwhelming Christian nature of the States is not hard to evidence. While dismantling such a relationship requires deep historical engagement, ensuring certain neutrality in the public square, or the making of specific overtures towards particular religions should not be as difficult a frontier to overcome. At the most basic level the State would have obligations to all its citizens irrespective of their religion to ensure access to rights without discrimination, including positive action where structural discrimination has become ossified and intractable. Europe has been loath to adopt quotas, but this may be the time to re-invoke that discussion, in designing measures to apply to a wide set of disenfranchised communities, including religious minorities and others who face entrenched discrimination. These principles are well enshrined in legal systems around the globe but attention must be paid to their consistent upholding. Beyond that, ensuring that the public square is free from hate as indicated above would ensure that all religious and other communities, whether they be nationals of the state or not are protected.

\section{(e) Minority Rights as a Litmus Test for systemic efficacy}

If European societies are to emerge rejuvenated from the multiple challenges that have beset the first two decades of this century, there has to be realization of the need for inclusivity to benefit from the rich and diverse talent that is now within these communities. Minority rights becomes an important barometer for the extent of this inclusivity with religious and ethno-racial minorities, alongside linguistically different communities being its obvious constituents. Emphasizing the systematization of the equality of opportunity and testing its efficacy against key identity markers is fundamental to progress. This is not only about ensuring greater religious freedoms, but equally about ensuring that religious minorities are able to access and thrive within all walks of life, institutions and spheres of influence. It involves making the necessary changes to societal visions of itself, but 
some emphasis needs also to be placed on attempts to recalibrate the flawed inaccurate narratives of the past that are used as doctrine to inform manufactured realities about the legitimacy of European actions against others. The presence of so many communities who originate beyond Europe but are now firmly entrenched within its shores will give Europe a natural comparative advantage over many other regions of the world, where the necessity may exist but the means may be lacking. Europe's religious and other minorities are likely to be its biggest assets in building a sustainable future, especially in reaching out to parts of the world where they have heritage. Embracing this and participating in the building of new contemporary national compacts based on shared not differentiated values, in return for guaranteed access to universal rights and a genuine attempt to benefit from diversity by ensuring equality of opportunity to all is likely to be the best route for true social and planetary sustainability.

Author Contributions: All authors contributed equally to this paper. All authors have read and agreed to the published version of the manuscript.

Funding: This research received no external funding.

Conflicts of Interest: The authors declare no conflict of interests.

\section{References}

Bobowik, Magdalena, Joaquim Pires Valentim, and Laurent Licata. 2018. Introduction to the Special Issue: Colonial Past and Intercultural Relations. International Journal of Intercultural Relations 62: 1-12. [CrossRef]

Carey, Henry C. 2018. Commerce, Christianity and Civilization versus British Free Trade: Letters in Reply to the London Times. New York: Franklin Classics.

Castellino, Joshua. 2008. Territorial Integrity and the "Right" to Self-Determination: An Examination of the Conceptual Tools. Brooklyn Journal of International Law 33: 503. Available online: https://brooklynworks.brooklaw.edu/bjil/vol33/iss2/15 (accessed on 21 September 2021).

Castellino, Joshua. 2020a. Colonial Crime, Environmental Destruction and Indigenous Peoples: A Roadmap to Accountability and Protection. In Colonial Wrongs and Access to International Law. Edited by Morten Bergsmo, Wolfgang Kaleck and Kyaw Yin Hlaing. Brussels: Torkel Opsahl Academic EPublisher, Available online: https:/ /www.legal-tools.org/doc/2rkcrx/pdf (accessed on 24 February 2021).

Castellino, Joshua. 2020b. The Rise of Majorities and Emerging Existential Threats to India and China. The Chinese Journal of Comparative Law 8: 538-57. [CrossRef]

Chin, Rita. 2017. The Crisis of Multiculturalism in Europe: A History. Princeton: Princeton University Press.

Choudhary, Vikas K. 2021. The Idea of Religious Minorities and Social Cohesion in India's Constitution: Reflections on the Indian Experience. Religions 12: 910. [CrossRef]

Deutsch, Karl W., and William J. Foltz. 1966. Nation Building in Comparative Contexts. New York: Routledge.

Devine, Karen. 2011. Neutrality and the Development of the European Union's Common Security and Defence Policy: Compatible or Competing? Cooperation and Conflict 46: 334-69. [CrossRef]

Domínguez, Lara, and Colin Luoma. 2020. Decolonising Conservation Policy: How Colonial Land and Conservation Ideologies Persist and Perpetuate Indigenous Injustices at the Expense of the Environment. Land 9: 65. [CrossRef]

Henrard, Kristin. 2021. EU Law's Half-Hearted Protection of Religious Minorities Minority Specific Rights and Freedom of Religion for All. Religions 12: 830. [CrossRef]

Hopkins, Anthony G. 2000. Quas-States, Weak States and the Partition of Africa. Review of International Studies 26: 311-20. [CrossRef]

Jennings, Robert Y. 1963. The Acquisition of Territory in International Law. Manchester: Manchester University Press, New York: Oceana Publications Inc.

Khosla, Madhav. 2020. India's Founding Moment: The Constitution of as Most Surprising Democracy. Harvard: Harvard University Press.

Klerman, Daniel M., Paul G. Mahoney, Holger Spamann, and Mark I. Weinstein. 2011. Legal Origin or Colonial History? Journal of Legal Analysis 3: 379-409. [CrossRef]

NoiseCat, Julian Brave. 2017. The Western Idea of Private Property is Flawed. Indigenous Peoples have it Right. The Guardian Newspaper, March 27. Available online: https:/ /www.theguardian.com/commentisfree/2017/mar/27/western-idea-privateproperty-flawed-indigenous-peoples-have-it-right (accessed on 13 February 2021).

Ochoa Jiménez, María Julia. 2019. Conflict of Laws and the Return of Indigenous Peoples' Cultural Property: A Latin American Perspective. International Journal of Cultural Property 26: 437-56. [CrossRef]

Orakhelashvili, Alexander. 2006. The Idea of European International Law. European Journal of International Law 17: 315-47. [CrossRef]

Parekh, Bhikhu. 2009. The Constitution as a Statement of Indian Identity. In Politics \& Ethics of the Indian Constitution. Edited by Rajeev Bhargava. New Delhi: Oxford University Press. 
Sharkey, Heather. 2018. History Rhymes? Late Ottoman Millets and Post-Ottoman Minorities in the Middle East. International Journal of Middle East Studies 50: 760-64. [CrossRef]

Sieder, Rachel. 2012. The Challenge of Indigenous Legal Systems: Beyond Paradigms of Recognition. The Brown Journal of World Affairs 18: 103-14.

Xanthaki, Alexandra, and Alexandra Tomaselli. 2021. The Struggle of Indigenous Peoples to Maintain Their Spirituality in Latin America: Freedom of and from Religion(s), and Other Threats. Religions 12: 869. [CrossRef] 